DRAM: A MODEL OF HEALTH CARE RESOURCE ALLOCATION IN CZECHOSLOVAKIA

\author{
P. Aspden \\ Her Majesty's Treasury, London, United Kingdom \\ L. Mayhew \\ International Institute for Applied Systems Analysis, Laxenburg, Austria \\ M. Rusnak \\ Institute of Medical Bionics, Bratislava, Czechoslovakia
}

RR-82-6

February 1982

Reprinted from OMEGA: The International Journal of Management Science, volume 9(5) (1981)

INTERNATIONAL INSTITUTE FOR APPLIED SYSTEMS ANALYSIS

Laxenburg, Austria 
Research Reports, which record research conducted at IIASA, are independently reviewed before publication. However, the views and opinions they express are not necessarily those of the Institute or the National Member Organizations that support it.

Reprinted with permission from OMEGA: The International Journal of Management Science 9(5): 509-518.

Copyright $\odot$ British Crown Copyright 1981.

All rights reserved. No part of this publication may be reproduced or transmitted in any form or by any means, electronic or mechanical, including photocopy, recording, or any information storage or retrieval system, without permission in writing from the copyright holder. 


\section{FOREWORD}

The principal aim of health-care research at the International Institute for Applied Systems Analysis is to meet an important need of health-service planners by developing and testing a family of submodels dealing with aspects of national health-care systems. The work involves building linked submodels dealing with population, disease prevalence, and resource needs, allocations, and supply.

DRAM (the Disaggregated Resource Allocation Model) was developed to simulate the behavior of a health-care system when resource levels change; it exhibits the effects of such changes on the number of patients treated and the quality of care they receive.

The model has been applied with reasonable success in several countries, indicating that it is versatile enough to deal with such a problem in a variety of contexts. This paper presents the results that were obtained when DRAM was applied to Czechoslovakian data.

An appendix lists related publications.

ANDREI ROGERS

Chairman

Human Settlements and Services Area 


\title{
DRAM : a Model of Health Care Resource Allocation in Czechoslovakia
}

\author{
P ASPDEN \\ HM Treasury, London, UK \\ L MAYHEW \\ Institute for Applied Systems Analysis, Laxenburg, Austria \\ M RUSNAK \\ Institute of Medical Bionics, Bratislava, Czechoslovakia \\ (Received May 1981)

\begin{abstract}
This paper presents an application to data from Czechoslovakia of a health care resource allocation model called DRAM (Disaggregated Resource Allocation Model). DRAM was developed by the health care systems modelling group at the International Institute for Applied Systems Analysis (IIASA). It attempts to predict the consequences of resource-level changes, in terms of the numbers of patients treated in each clinical category and the quality of care they receive in each mode of treatment. In this application, seven acute clinical categories and two types of resources (hospital doctors and hospital beds) are selected for examination in one mode of treatment-in-patient care. Some parallels are drawn with a comparable application in the UK.
\end{abstract}

A PRESSING problem affecting all countries today is the ever-increasing amount of resources being allocated to health care. Nobody knows exactly what marginal benefits this increased spending is bringing; nobody is certain what should be done to control it. Attempts by governments or official agencies to moderate or cut back on spending necessarily affects the different groups in the health care system in different ways. Any indication of the potential consequences such attempts at control may entail, therefore, are obviously beneficial for decision making purposes and for the framing of appropriate government policies. The present paper reports some applied work in this field carried out jointly between the health care systems modelling group at the International Institute for Applied

(C) British Crown Copyright 1981.
Systems Analysis and the Institute of Bionics in Bratislava, Czechoslovakia. It concerns the application of DRAM (Disaggregated Resource Allocation Model) to the Czechoslovakian intake of hospital in-patients. The details of the work are reported by Aspden \& Rusnak [1]. A summary of the results has been presented at the Fifth European Meeting on Cybernetics and Systems Research, Vienna, April 1980 [10].

DRAM is a behavioural model developed at IIASA in conjunction with the Operational Research Services of the Department of Health and Social Security (DHSS) in London, England. It was designed to simulate how the health care system (HCS) in aggregate allocates limited supplies of resources between competing demands. The outputs of the model are the numbers of people cared for in each care group, and within each care group the distribu- 
tion between the alternative forms ('modes') of care. The model also gives the level of resources allocated to each person. The theoretical basis and the model have been formulated and discussed in [2] and developed further in [3]. The model assumes two things: firstly, that there are never enough resources to satisfy all the demands made on the HCS; and secondly, that the aggregate behaviour of the HCS can be represented by a unity function whose parameters can be inferred from past resource allocations. The model is currently being tested by groups in several countries other than Czechoslovakia, and some results from this work are now available for comparison [4-6]. In general, these results indicate the broad applicability of the model to different sectors of the HCS (acute care or care for the chronically ill), and to countries (such as Canada and the UK) with substantially different philosophies of health care provision. In what follows we discuss an application to the in-patient acute sector of the Czechoslovakian HCS and make some simple comparisons with an application of DRAM based on UK data [5]. Before proceeding, however, some background on the Czechoslovakian system of health care provision helps to put this work into perspective.

\section{HEALTH CARE PROVISION IN CZECHOSLOVAKIA}

The first organized medical care in the region now covered by Czechoslovakia was provided by a hospital established in Prague in $980 \mathrm{AD}$. In the period up to 1918 when the Republic of Czechoslovakia was formally constituted, the region remained in the forefront of medical education and technology. During the Second World War, a clandestine group of doctors, led by Doc.MUDr. M. Nevěd (later killed as a result of the War) proposed a new conception of health care and medical education that later became the model for the post-war reconstruction. In 1948 a new constitution established free access to proper medical care as the right of all citizens. Organized on socialist guidelines, the resultant system was based on the unity of therapeutic and preventive care under governmental supervision.

In 1966, new legislation was enacted giving the HCS its present structure. The basic terri- torial units of health care provision today are the Health Districts (Zdravotnícke Obvody). These each contain about 6000 citizens and are served principally by general practitioners. Therapeutic and preventive care in this sector of the system is provided by hospitals and polyclinics on an in-patient and ambulatory basis. Hospital catchment areas (Spadove Uzemie) comprise the Health Districts and are of three types depending on the size and specialization of hospital. Type I provides for general clinical specialties and serves populations of up to 50,000 ; type II provides for both general and more specialized functions and serves up to 200,000; and type III incorporates very specialized services and teaching functions and serves populations up to 1 million. To give some orders of magnitude: there are approximately 15 million people in Czechoslovakia, 230 hospitals (plus 200 related therapeutic institutes), 185,000 hospital beds, and 39,000 medical doctors. In 1977 the hospitals treated approximately 2.5 million in-patients.

\section{THE INSTITUTIONAL FRAMEWORK OF THE CSSR}

Czechoslovakia is a federation of two states: the Czech Socialist Republic (CSR) and the Slovak Socialist Republic (SSR). Each state has a separate ministry of health responsible for long-range planning and day-to-day running of the HCS. The CSR is divided for administrative purposes into eight regions and the SSR into four. Assisting the ministries are a number of specialized research institutes whose scientists work on problems confronting the HCS. One example is the Institute of Medical Bionics (Vyskumny Ustav Lakarskej Bioniky) set up in 1967 in Bratislava, the capital city of Slovakia. Its main aim is the application of the principles of cybernetics to problems in the medical field. In recent years, encouraged by the Slovakian Ministry of Health and in conjunction with other institutes in Czechoslovakia and other countries, the Institute has developed greater interest in applying this paradigm to the managerial aspects of the HCS. One outcome of this is the current collaboration with the health care systems modelling group at IIASA, in particular the application of the resource allocation model, DRAM [1] to 1976 Czechoslovakian data. 


\section{THE MODEL IN BRIEF}

The question which DRAM asks can be concisely stated as follows: given a bundle of resources, how will the HCS allocate them among competing demands? To answer this question DRAM assumes a utility function describing the aggregate behaviour of the system that is stated in mathematical terms as follows:

Let

$x_{j k}=$ number of individuals in the $j$ th patient category who receive resources in the $k$ th mode of care (per head of population per year)

$X_{j k}=$ the ideal number of individuals in the $j$ th patient category who should receive resources in the $k$ th mode of care (per head of population per year) assuming no constraint on resource availability

$y_{j k l}=$ the supply of resource type $l$ received by each individual in the $j$ th patient category in the $k$ th mode of care

$Y_{j k l}=$ the ideal level of supply of resource $l$ for each individual in the $j$ th patient category in the $k$ th mode of care assuming no constraint on resource availability

$R_{l}=$ the availability of resource type $l$ (per head of population per year)

$C_{l}=$ marginal cost of resource $l$ when all demands are satisfied

then the utility function which the various agents in the HCS seek to maximize is taken to be

$$
Z(x, y)=\sum_{j} \sum_{k} g_{j k}\left(x_{j k}\right)+\sum_{j} \sum_{k} \sum_{l} x_{j k} h_{j k l}\left(y_{j k l}\right)
$$

subject to

$$
\sum_{j} \sum_{k} x_{j k} y_{j k l}=R_{l} \quad \forall l
$$

where

$$
\begin{array}{r}
g_{j k}(x)=\frac{\sum_{l} C_{l} X_{j k} Y_{j k l}}{x_{j}}\left\{1-\left(\frac{x}{X_{j k}}\right)^{-x_{j}}\right\} \\
h_{j k l}(y)=\frac{C_{l} Y_{j k l}}{\beta_{j k l}}\left\{1-\left(\frac{y}{Y_{j k l}}\right)^{-\beta_{j k l}}\right\}
\end{array}
$$

$\alpha_{j}(>0)$ is a parameter measuring the relative importance of treating the ideal number of individuals $X_{j k} . \beta_{j k l}(>0)$ is a parameter measur- ing the relative importance of achieving the ideal level of $Y_{j k l}$. The utility function $Z$ depicts the many agents who control the allocation of health care resources as seeking to attain ideal levels of service $(X)$ and supply $(Y)$, but where the urge to increase the actual levels of service $(x)$ and supply $(y)$ decreases with increasing values of $x$ and $y$, according to the parameters $\alpha$ and $\beta$. The costs of different resources are introduced so that the marginal increases in $Z$, when ideal levels are achieved $(x=X, y=Y)$, equal the marginal resource costs. Beyond these levels, extra resources are only useful as assets and not for treating patients.

It is shown in [2] that the solution of the optimization problem in equation (1) is as follows

$$
\begin{gathered}
y_{j k l}=Y_{j k l} \lambda_{l}-1 /\left(\beta_{j k l}+1\right) \\
x_{j k}=X_{j k} \mu_{j k}^{-1 /\left(x_{j}+1\right)}
\end{gathered}
$$

where $\mu_{j k}$ is a weighted sum

$$
\mu_{j k}=\frac{\sum_{l} C_{l} Y_{j k l} v_{j k l}}{\sum_{l} C_{l} Y_{j k l}}
$$

of the terms

$$
v_{j k l}=\left(\left(\beta_{j k l}+1\right) \lambda \beta^{\beta_{k l} l\left(\beta_{j k l}+1\right)}-1\right) / \beta_{j k l}
$$

and where $\lambda_{l}$, the Lagrange multipliers, are the solutions of the following set of equations

$$
0=-R_{l}+\sum_{j} \sum_{k} X_{j k} Y_{j k l} \bar{\pi}_{l}^{-1 /\left(\mu_{j k l}+1\right)} \mu_{j k}^{-1 / 2 j+1)} \text { for all } l \text {. }
$$

The algorithm for determining the solutions (equations (2) and (3)) has been developed by Hughes and Wierzbicki [3]. This algorithm has been programmed and requires no specialized software. Experience has shown that the computer programme can be transferred from computer to computer without much difficulty.

\section{APPLYING DRAM TO CZECHOSLOVAKIAN HOSPITAL IN-PATIENT DATA}

In this application of DRAM, the parameters $x, y, \alpha$ and $\beta$ were estimated from past resource allocations for a one mode model (inpatient care) with seven treatment categories and two resource types. Details of the algorithm for parameter estimation can be found in 
$[1,3]$. In some applications of DRAM a subset of $x, y, \alpha$ and $\beta$ may be known independently (e.g. from special surveys). Reference [2] gives examples of such cases.

\section{DATA REQUIREMENTS}

\section{(a) The treatment categories}

The treatment categories chosen for study take into account certain conditions imposed by the parameter estimation process. The most important of these is that each of the administrative regions ( 12 in all) be approximately selfsufficient in resources for each clinical speciality. This is necessary because the utility function $z(x, y)$ is assumed to apply in each region independently, and unless corrections are made for cross-boundary hospital admissions, distortions will occur in the parameter estimates. As a result of this, and of other considerations, the following seven categories were chosen: general surgery; general medicine; obstetrics and gynaecology; traumatic and orthopaedic surgery; otorhinolaryngology; paediatrics; and ophthalmology. These categories are currently among the largest acute specialities not only in Czechoslovakia but also elsewhere in the developed world. The data on hospital admission rates for each category in each region in 1976 was taken from CSSR Zdravotnictvi [7, p. 189], a comprehensive volume of Czechoslovakian health care statistics.

\section{(b) Resource measures}

The important resource indictors affecting the standard and quality of in-patient care are generally agreed to be hospital beds and doctors, nurses and operating theatres. Considerable evidence has been accumulated regarding the effects on admission rates to hospital of the first two e.g. $[8,9]$; less is known, however, about the effects of the other two resources, and probably some more preliminary analysis is needed on them before they can be used in this model. For current purposes therefore, DRAM was calibrated in the basis of only bed and doctor availability. The first resource, hospital beds, was measured as available beds per 1000 population. This meant that the supply variable $\left(y_{j k l}\right)$ had units measured in the available bed-days per patient. The second resource, doctor supply, is more complicated and a number of definitions were examined. The eventual measure selected was the number of doctors of all grades belonging to the specialties listed in section (a) above. The necessary data for this resource were also taken from CSSR Zdravotnictvi [7, pp. 217-219]. The units used were doctor-days per 1000 population (one doctor-year $=225$ doctor-days).

In Table 1 the resource availability on both measures - beds and doctors - are set out for the twelve administrative regions of Czechoslovakia. The table displays a sufficiently wide range of values to make an efficient estimation

Table 1. Resource availabilities for the SEVEN tReatment Categories-Czechoslovakia $1976^{*}$

\begin{tabular}{lcc}
\hline \multicolumn{1}{c}{ Region } & $\begin{array}{c}\text { Available bed-days } \\
\text { per 1000 population } \\
\text { (1 bed-year }=365 \text { bed-days) }\end{array}$ & $\begin{array}{c}\text { Hospital doctor-days } \\
\text { per 1000 population } \\
\text { (1 doc-year = 225 doc-days) }\end{array}$ \\
\hline Praha & 2271 & 91 \\
Stredocesky & 2634 & 111 \\
Jihoscesky & 2312 & 96 \\
Zapadocesky & 2355 & 96 \\
Severocesky & 2435 & 112 \\
Vychodocesky & 2525 & 86 \\
Jihomoravsky & 1970 & 79 \\
Severomoravsky & 2352 & 98 \\
Bratislava & 960 & 61 \\
Zapadoslovensky & 1715 & 107 \\
Stredoslovensky & 1799 & 107 \\
Vychodoslovensky & 1870 & \\
\hline
\end{tabular}

* Source: [1]. 
of the model, and it is to the results from the calibration process that attention now turns.

\section{PARAMETER ESTIMATION}

Estimates are required in DRAM for three groups of parameters:

(1) The ideal levels $X, Y$ at which patients would be admitted and would receive resources were there no constraints on resource availability.

(2) The power parameters $\alpha, \beta$ which reflect the relative importance of achieving the ideal levels $X$ and $Y$ (for instance, if an $\alpha_{j}$ is relatively high then it is relatively more important to achieve the corresponding $X$ ).

(3) The relative costs of $C$ of the different resources - in this case hospital beds and hospital doctors.

In gauging the effectiveness of DRAM in replicating the observations, it is useful to define measures of goodness-of-fit. The measures used are defined below.

The notation for an actual data point $i$ (a region in Czechoslovakia) is written $x_{j}(i), y_{j l}(i)$ (for a one-mode model the subscript $k$ is unnecessary). The amount of resource type $l$ used in $i$ is hence

$$
\sum_{j} x_{j}(i) y_{j l}(i)=R_{l}(i)
$$

Let $\hat{x}_{j}(i)$ and $\hat{y}_{j l}(i)$ be the values predicted by the model for a particular parameter set $(X, Y, \alpha, \beta)$. Then

$$
S S \hat{x}_{j}=\sum_{i}\left(\frac{x_{j}(i)-\hat{x}_{f}(i)}{W_{j}}\right)^{2}
$$

and

$$
S S \hat{y}_{j t}=\sum_{i}\left(\frac{y_{j l}(i)-\hat{y}_{j l}(i)}{V_{j l}}\right)^{2}
$$

where $W_{j}$ is a weighted average of $x_{j}(i)$ and $V_{j l}$ is a weighted average of $y_{j l}(i)$. These equations represent the variances of the estimates about the actual values. They are usefully compared with another set of variances this time constructed about the weighted averages themselves; OMEGA 9/5-E namely

$$
\begin{aligned}
& S S \bar{x}_{j l}=\sum_{i}\left(\frac{x_{j}(i)-W_{j}}{W_{j}}\right)^{2} \\
& S S \bar{y}_{j l}=\sum_{i}\left(\frac{y_{j l}(i)-V_{j l}}{V_{j l}}\right)^{2}
\end{aligned}
$$

Clearly, it is desirable, if the model is to perform well, for the first set of variances to be substantially less than the second set. In the event that the first variance set is greater, it means that a simple weighted average of the data set is probably a better estimator of the actual observations than the model itself.

\section{THE DETERMINATION OF RELATIVE RESOURCE COSTS}

In a multiple resource model the relative costs as between the resources must also be specified at the point when all demands in the HCS are satisfied - that is, when the ideal levels $X, Y$ are achieved. For present purposes, it was assumed that the marginal costs of the two resources, hospital beds and hospital doctors, are the same for current intermediate resource levels as for the resource levels needed to satisfy all demands for health care. (For other aspects to this problem see [3, p. 30]). This approach greatly simplified the necessary estimation procedure. This was carried out using the following linear model based on data on the 12 regions taken from the same source as above [7]. The hypothesis was:

$$
\begin{aligned}
\text { Total hospital costs }=\text { constant } \\
+(\text { cost of bed-year }) \times(\text { No. of bed-years }) \\
+(\text { cost of doctor-year }) \times(\text { No. of doctor-years })
\end{aligned}
$$

From this model, which was estimated using ordinary least squares regression, the coefficients gave the following relationship:

$$
\begin{aligned}
1 \text { doctor-day } & =5 \text { bed-days } \\
\text { where } \quad \text { one bed-year } & =365 \text { days } \\
\text { and } \quad \text { one doctor-year } & =225 \text { doctor-days }
\end{aligned}
$$

\section{THE MAIN PARAMETER ESTIMATES}

With the above empirical result and the original data set, the main DRAM parameters $(X$, $Y, \alpha, \beta)$ were then estimated. The results are 
TABLE 2. Two-Resource (HOSPITAL BedS AND hosPital DOCTORS) DRAM PARAMETER ESTIMATES OF CZECHOSLOVAKIAN HOSPITAL IN-PATIENT CARE

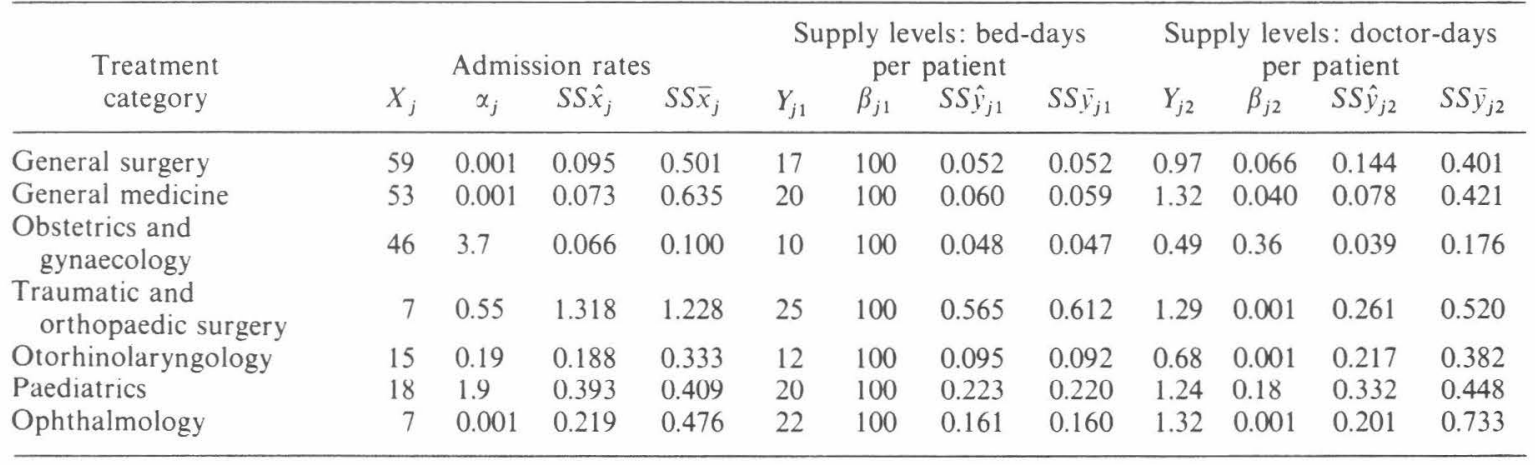

given in Table 2. Looking first at the admission rates, we note that the $S S \hat{x}_{j}$ are much smaller than $S S \bar{x}_{j}$ for the treatment categories general medicine and general surgery, implying that here DRAM is replicating the data very well. For traumatic and orthopaedic surgery and paediatrics, however, the $S S \hat{x}_{j}$ approximately equal the $S S \bar{x}_{j}$ indicating a much poorer performance in these instances. For the remaining three categories the model does reasonably well, with values of the $S S \hat{x}_{j}$ about half those of the corresponding $S S \bar{x}_{j}$.

Let us now examine the $\alpha_{j}$, the elasticities of the admission rates to resource supply. Low $\alpha_{j}$ indicate a high elasticity to variations in resource levels, as is known to be the case for general medicine $\left(\alpha_{j}=0.001\right)$. For obstetrics and gynaecology $\left(\alpha_{j}=3.7\right)$ the opposite result is true, suggesting that admission rates in this instance change relatively less with regard to supply levels.

In terms of the bed-days supplied to each patient (resource 1), the results showed a very great inelasticity to changes in bed availability (and as a result all the $\beta_{j 1}$ were fixed at 100 , an arbitrarily high value). This action may be jus- tified if simple plots are made for each speciality of bed-days per patient on the available bed-days in each region per 1000 population, $R_{1}(i)$. In none of the categories is there a clear increasing trend (Fig. 1). For the second resource, doctor-days per patient, the model captured the variations between the patient categories with reasonable effectiveness.

It is of interest to contrast these results with those obtained when the model was calibrated from data from the South West Regional Health Authority (SWRHA), in the United Kingdom. Table 3 gives the two sets of parameters. Consider first how well each model calibration reproduces actual results by patient category. If the patient categories are ordered by the measure

$$
\frac{S S \hat{x}_{j}}{S S \bar{x}_{j}}+\frac{S S \hat{y}_{j 1}}{S S \bar{y}_{j 1}}+\frac{S S \hat{y}_{j 1}}{S S \bar{y}_{j 2}}(\text { see Table 4) }
$$

then the following rankings are produced (lowest first)

\section{Czechoslovakia}

General medicine

Table 3. A comparison of parameter values obtained in Czechoslovakia and the UK

\begin{tabular}{|c|c|c|c|c|c|c|c|c|c|c|c|c|}
\hline \multirow{2}{*}{$\begin{array}{l}\text { Treatment } \\
\text { category }\end{array}$} & \multicolumn{6}{|c|}{ Czechoslovakia } & \multicolumn{6}{|c|}{ South West Health Authority, UK } \\
\hline & $X_{j}$ & $x_{j}$ & $Y_{j 1}$ & $\beta_{j 1}$ & $Y_{j 2}$ & $\beta_{j 2}$ & $X_{j}$ & $x_{j}$ & $Y_{j 1}$ & $\beta_{j 1}$ & $Y_{j 2}$ & $\beta_{j 2}$ \\
\hline General surgery & 59 & 0.001 & 17 & 100 & 0.97 & 0.066 & 23 & 5.7 & 15 & 0.51 & 0.25 & 0.212 \\
\hline General medicine & 53 & 0.001 & 20 & 100 & 1.32 & 0.040 & 28 & 0.001 & 19 & 0.53 & 0.28 & 0.078 \\
\hline $\begin{array}{l}\text { Obstetrics and } \\
\text { gynaecology }\end{array}$ & 46 & 3.7 & 10 & 100 & 0.49 & 0.36 & 24 & 2.7 & 8.6 & 8.3 & 0.22 & 0.293 \\
\hline $\begin{array}{l}\text { Traumatic and } \\
\text { orthopaedic surgery }\end{array}$ & 7 & 0.55 & 25 & 100 & 1.29 & 0.001 & 12 & 2.2 & 21 & 1.9 & 0.39 & 0.096 \\
\hline Otorhinolaryngology & 15 & 0.19 & 12 & 100 & 0.68 & 0.001 & 5.9 & 1.0 & 16 & 0.001 & 0.70 & 0.756 \\
\hline Paediatrics & 18 & 1.9 & 20 & 100 & 1.24 & 0.18 & 12 & 0.001 & 17 & 1.0 & 0.37 & 0.372 \\
\hline Ophthalmology & 7 & 0.001 & 22 & 100 & 1.32 & 0.001 & 26 & 5.0 & 16 & 1.0 & 1.1 & 0.843 \\
\hline
\end{tabular}




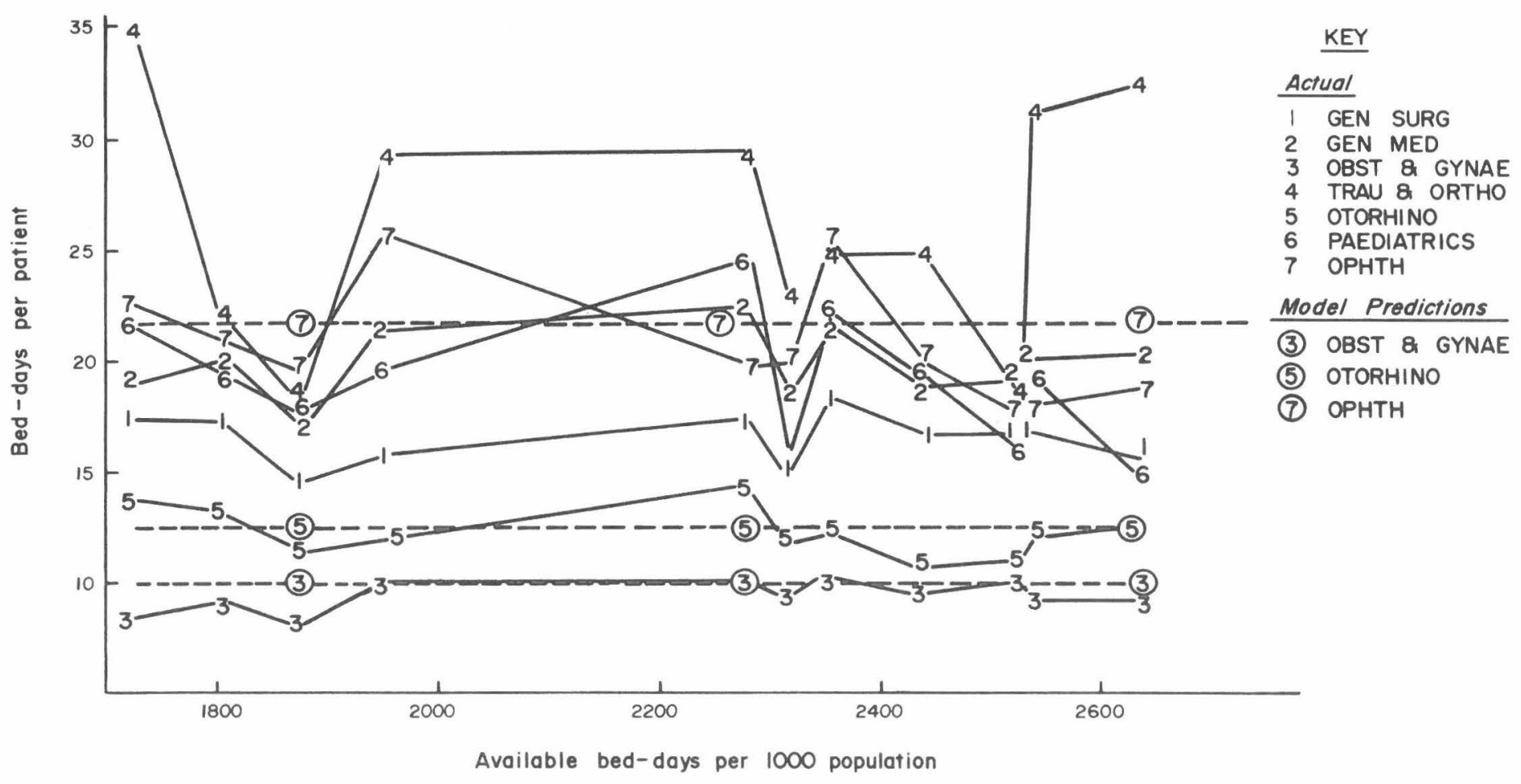

FiG. 1. Supply levels (beds)-1976. 
TABLE 4. COMPARISON OF RATIOS SS $\hat{x} / S S \bar{x}$ AND $S S \hat{y} / S S \bar{y}$

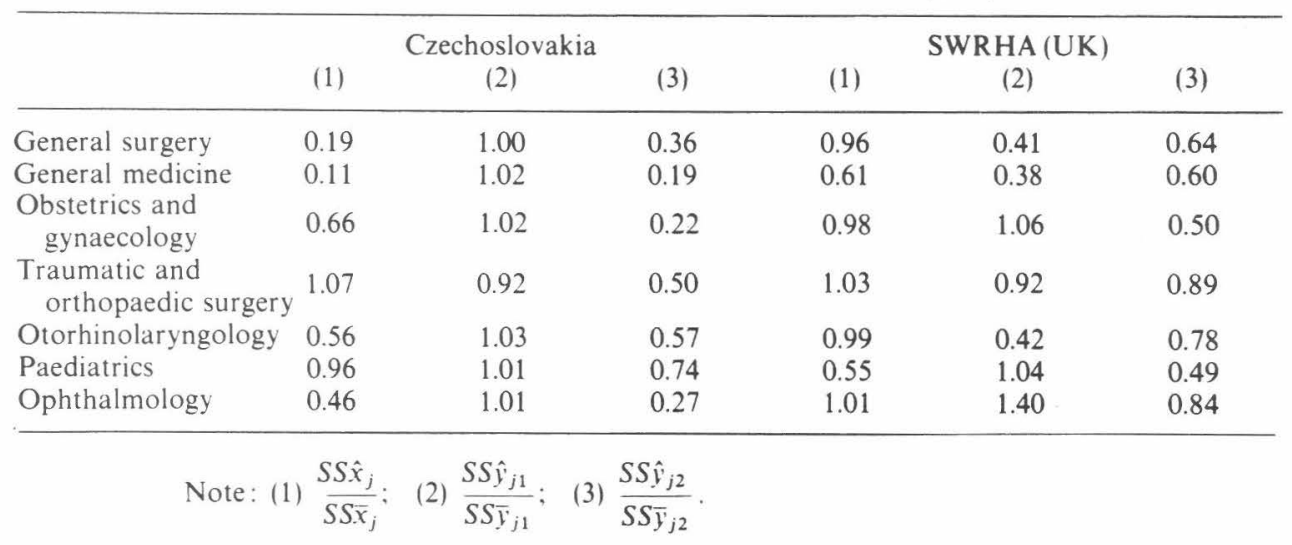

General surgery

Ophthalmology

Obstetrics and Gynaecology

Otorhinolaryngology

Traumatic and Orthopaedic surgery

Paediatrics

SWRHA (UK)

General medicine

Paediatrics

General surgery

Otorhinolaryngology

Obstetrics and Gynaecology

Traumatic and Orthopaedic surgery

Ophthalmology

These lists would be very similar if paediatrics and ophthalmology were switched. This suggests the hypothesis that the levels of hospital beds and doctors are relatively important for forecasting admission rates and supply levels per patient for general surgery and general medicine and relatively unimportant for forecasting traumatic and orthopaedic surgery.

A further point of contrast from these separate applications of DRAM are the large differences (Table 3 ) estimated for the ideal admission rates, $X_{j}$. For general surgery, general medicine, obstetrics and gynaecology, otorhinolaryngology and paediatrics, these are about twice as high in Czechoslovakia as in the SWRHA. The ideal supply levels, $y_{j l}$, show more concurrence in the case of bed-days per patient, though again they are less in the SWRHA. The ideal doctor-days per patient cannot be compared because of differences of definition in the unit of resource measure. The general importance attached by each HCS to the respective treatment categories can be compared by examining the orderings of $\alpha_{j}$ (and $\beta_{j l}$ ) within each system. Here no clear picture emerges. Clearly the validity of all the above comparisons must depend on the degree to which the definitions of treatment categories coincide.

Now that the parameter estimates have been made, and some simple comparisons undertaken, it is desirable to look at them with a more critical eye. Reference [1] considered the degree to which the Czechoslovakian tworesource model reproduced observed behaviour compared with the results of models calibrated for each resource separately. The results indicated that the supply of hospital beds was a more important factor in reproducing the behavior of admission rates than the supply of hospital doctors. Both the models including hospital beds as a resource type did not seem to be able to reproduce the variation in beddays per patient. In addition, the model with hospital doctors as resource type did not seem to be able to reproduce the variation in doctordays per patient. However, when this resource type was taken in conjunction with the supply of hospital beds, DRAM was able to reproduce much of the variation in doctor-days per patient. In addition, as we have already observed, the degree to which the two-resource model was able to reproduce actual resource allocations varied with patient category. These observations suggest that there are interactions taking place in the HCS not explained by these two resources alone. On the other hand, the problems with the calibration may lie not with 
the resource specification but with the data set and some of the assumptions that were made at the outset. To refine the calibration further therefore, and before giving an illustrative prediction run from the current two-resource model, the following suggestions and refinements are being considered for the next stages in this work.

(a) To consider whether other resources (or modes of care) should be introduced to give better explanations of the data set

(b) To consider whether there are resource measures of hospital beds and hospital doctors that are better than the ones chosen

(c) To introduce more specialities but at the same time correcting for those cross-boundary flows which can introduce a bias into the parameter estimation.

\section{ILLUSTRATIVE MODEL VALIDATION AND PREDICTIONS}

Once parameter estimates for Czechoslovakia had been obtained, it was then possible to use the model for observing the behaviour of the system when resource levels were changed. In a proper medical context, of course the possibility that some or all of the parameter set $(X, Y, \alpha, \beta)$ can change in time should be given careful attention. For example, the lengths of stay in many specialities are falling, and normally it would be desirable to include these trends in predictive runs. In the current illustration, however, the parameter set is for simplicity taken to be constant.

In 1976, the resource allocations in the seven treatment categories for Czechoslovakia were 2119 bed-days per 1000 population and 96 hospital doctor-days per 1000 population. Table 5 , columns one and two, demonstrate the close-

Table 5. Allocations of health Care resources in Czechoslovakia

\begin{tabular}{|c|c|c|c|}
\hline Treatment category & $\begin{array}{c}\text { Actual allocation } \\
\text { for } 1976 \\
R_{1}=2119 \text { bed-days } \\
\text { per } 1000 \text { pop. } \\
R_{2}=95.6 \text { doctor- } \\
\text { days per } 1000 \\
\text { pop. }\end{array}$ & $\begin{array}{c}\text { Model prediction } \\
R_{1}=2119 \text { bed-days } \\
\text { per } 1000 \text { pop. } \\
R_{2}=95.6 \text { doctor- } \\
\text { days per } 1000 \\
\text { pop. }\end{array}$ & $\begin{array}{l}\text { Model prediction } \\
R_{1}=1800 \text { bed-days } \\
\text { per } 1000 \text { pop. } \\
R_{2}=110 \text { doctor- } \\
\text { days per } 1000 \\
\text { pop. }\end{array}$ \\
\hline \multicolumn{4}{|l|}{ Admission rates per 1000 pop. } \\
\hline General surgery & 33.1 & 32.1 & 25.7 \\
\hline General medicine & 30.1 & 29.0 & 23.4 \\
\hline Obstetrics \& gynaecology & 40.1 & 40.1 & 38.2 \\
\hline $\mathrm{T} \& \mathrm{O}$ surgery & 4.2 & 4.7 & 4.0 \\
\hline Otorhinolaryngology & 8.6 & 8.7 & 7.2 \\
\hline Paediatrics & 15.2 & 15.0 & 13.9 \\
\hline Ophthalmology & 4.1 & 4.0 & 3.2 \\
\hline \multicolumn{4}{|l|}{ Bed-days per patient } \\
\hline General surgery & 16.6 & 16.6 & 16.6 \\
\hline General medicine & 19.7 & 20.3 & 20.3 \\
\hline Obstetrics \& gynaecology & 9.5 & 9.8 & 9.7 \\
\hline $\mathrm{T} \& \mathrm{O}$ surgery & 24.4 & 25.3 & 25.2 \\
\hline Otorhinolaryngology & 12.4 & 12.4 & 12.3 \\
\hline Paediatrics & 19.5 & 19.5 & 19.4 \\
\hline Ophthalmology & 21.8 & 21.7 & 21.7 \\
\hline \multicolumn{4}{|l|}{ Doctor-days per patient } \\
\hline General surgery & 0.73 & 0.74 & 0.99 \\
\hline General medicine & 0.96 & 1.00 & 1.35 \\
\hline Obstetrics \& gynaecology & 0.40 & 0.40 & 0.50 \\
\hline $\mathrm{T} \& \mathrm{O}$ surgery & 0.98 & 0.96 & 1.32 \\
\hline Otorhinolaryngology & 0.53 & 0.51 & 0.70 \\
\hline Paediatrics & 0.94 & 0.97 & 1.27 \\
\hline Ophthalmology & 0.90 & 0.98 & 1.35 \\
\hline
\end{tabular}


ness with which DRAM is able to replicate the actual admission rates in each category, and the respective resources that were allocated. In column three, the predicted effects are shown of what happens when this resource mix is changed, so that instead there are now only 1800 bed-days per 1000 population but 110 doctor-days per 1000 population. The results indicate that in general fewer patients will be treated, but that the levels of doctor care per patient will rise. The extent of the changes, however, is different for each treatment category. For example, admission rates for general medicine and general surgery (low $\alpha_{i} \mathrm{~s}$ ) will fall by about $20 \%$, while those for obstetrics and gynaecology (high $\alpha_{j}$ ) will fall by $5 \%$.

It is also desirable to give consideration to the predictive accuracy of this model, and more details of a suitable methodology are shown in $[5$, p. 69] and [1, p. 47]. As for the sensitivity of $x_{j}$ and $y_{j l}$ to changes in parameter values, work has suggested [1] that the model solution is more sensitive to the ideal levels $(\mathrm{X}, \mathrm{Y})$ than it is to the parameters $\alpha, \beta$, which reflect the relative importance of achieving these levels. This means that critical consideration should be given to the ways in which the ideal levels are chosen or estimated before the model is used in practice.

\section{CONCLUSIONS}

This paper has reported joint work on the problem of in-patient health care resource allocation in Czechoslovakia carried out by the health care modelling group at IIASA and the Institute of Medical Bionics. It has covered the application of the model, DRAM, to a data set based on two resource categories, bed-days and doctor-days, and seven patient categories. The calibration of the model was discussed, and the results were compared with a similar application of the model in the UK. Some weaknesses in the results were identified, and suggestions were made for further work. The generally good ability of the model to replicate the original data set was then discussed. Finally, in an example of a predictive run the consequent changes in admission rates and resource allocations were shown of a change in the resource mix. Health care planners should find the model of use in addressing questions of changing levels of resources, not only in Czechoslovakia but also elsewhere in the world.

\section{ACKNOWLEDGEMENT}

The authors are indebted to Professor Jan Rusnak, Dr Sc., Director of the Institute of Medical Bionics, Bratislava, for his encouragement and assistance at every stage in the preparation of this paper. The authors would also like to thank members and colleagues from the South West Regional Health Authority, UK, the Institute of Biometry and Community Medicine, Exeter, UK, and the Operational Research Unit of the Department of Health and Social Security, UK, for providing data and advice for this study.

\section{REFERENCES}

1. AsPden P \& RUSNAK M (1980) The IIASA health care resource allocation submodel: WP-80-53. Model calibration for data from Czechoslovakia. International Institute for Applied Systems Analysis, Laxenburg. Austria.

2. GiBBS RJ (1978) The IIASA health care resource allocation submodel: Mark 1. RR-78-8. International Institute for Applied Systems Analysis, Laxenburg, Austria.

3. Hughes DJ \& WieRzBicki A (1980) DRAM: a model of health care resources. RR-80-23. International Institute for Applied Systems Analysis, Laxenburg, Austria.

4. Rousseau JM \& GiBBS RJ (1980) A model to assist planning the provision of hospital services. CP-80-3. International Institute for Applied Systems Analysis, Laxenburg, Austria.

5. ASPDEN P (1980) The IIASA health care resource allocation submodel: DRAM calibration for data from the South West Health Region, UK. WP-80-115. International Institute for Applied Systems Analysis, Laxenburg, Austria.

6. ASPDEN P, GibBS R \& BOWEN T (1980) DRAM balances care. WP-80-42. International Institute for Applied Systems Analysis, Laxenburg, Austria.

7. CSSR ZdRavotnictvi (1977) Czechoslovakian Year Book on 1976 Health Statistics. Prague \& Bratislava, Czechoslovakia.

8. Feldstein MS (1967) Economic Analysis for Health Services Efficiency. North-Holland, Amsterdam.

9. VAn der GaAG J, Rutten FFH \& Van PraAg BMS (1975) Determinants of hospital utilization in The Netherlands. Hlth Serv. Res. 10(3), 264-277.

10. AsPden P \& Rusnak M (1980) A model (DRAM) for allocating health care resources with application to hospital in-patient data from Czechoslovakia. Proc. of 5th European Meeting on Cybernetics and Systems Research, Vienna, Austria, April.

ADDRESS FOR CORRESPONDENCE: $\operatorname{Dr} P$ Aspden, Room 10/5, HM Treasury, Parliament Street, London, SW1. 


\section{RELATED PUBLICATIONS IN THE HEALTH CARE SYSTEMS TASK}

1. R.J. Gibbs, A Disaggregated Health Care Resource Allocation Sub-Model: Mark 1. RR-78-8.

2. R.J. Gibbs, Computer Programs for the IIASA Health Care Resource Allocation Sub-Model, Mark 1 - A User's Guide. WP-78-15.

3. D.J. Hughes, The IIASA Health Care Resource Allocation Sub-Model: Mark 2 The Allocation of Many Different Resources. RM-78-50.

4. D.J. Hughes, The IIASA Health Care Resource Allocation Sub-Model: Formulation of DRAM Mark 3. WP-7846.

5. D.J. Hughes, The IIASA Health Care Resource Allocation Submodel: Estimation of Parameters. RM-78-67.

6. D.J. Hughes, E.A. Nurminski, and G. Royston, Nondifferentiable Optimization Promotes Health Care. WP-79-90.

7. J-M. Rousseau and R.J. Gibbs, A Model to Assist Planning the Provision of Hospital Services. CP-80-3.

8. P. Aspden, R.J. Gibbs, and T. Bowen, DRAM Balances Care. WP-80-43.

9. P. Aspden and M. Rusnak, The IIASA Health Care Resource Allocation Submodel: Model Calibration for Data from Czechoslovakia. WP-80-53.

10. D.J. Hughes and A. Wierzbicki, DRAM: A Model of Health Care Resource Allocation. RR-80-23.

11. P. Aspden, The IIASA Health Care Resource Allocation Submodel: DRAM Calibration for Data from the South West Health Region, UK. WP-80-115.

12. L. Mayhew and A. Taket, RAMOS: A Model of Health Care Resource Allocation in Space. WP-80-125.

13. L. Mayhew, The Regional Planning of Health Care Services: RAMOS and RAMOS ${ }^{-1}$. WP-80-166.

14. L.D. Mayhew, DRAMOS: a Multi-Category Spatial Resource Allocation Model for Health Service Management and Planning. WP-81-39.

15. L. Mayhew and A. Taket, RAMOS: A Model Validation and Sensitivity Analysis. WP-81-100.

16. L. Mayhew and G. Leonardi, Equity, Efficiency, and Accessibility in Urban and Regional Health Care Systems. WP-81-102.

17. L. Mayhew, Automated Isochromes and the Location of Emergency Medical Services in Cities: A Note. WP-81-103. 
